MEI

II, vol. 1

\title{
La biblioteca del MuVIM: seis años de gestión (2004-2010) ${ }^{1}$
}

\author{
Ana $M^{a}$ Reig Ferrer
}

\begin{abstract}
Resumen
Se describe la gestión de la biblioteca del MuVIM desde su creación. Una biblioteca de museo especializada en el pensamiento ilustrado pero que, al mismo tiempo, busca en la materialidad de los libros una proyección de futuro que le permita encontrar un espacio

Recibido el 01-11-2010 en la sociedad.

Aceptado en 18-12-2010

\section{Palabras Clave}

MuVIM; Bibliotecas especializadas; Museos; Ilustración; Diseño gráfico.

The library MuVIM : Six Years of Management (2004-2010) 1

Abstract

This paper describes the management of the MuVIM library since its creation. This is the library of a museum that specializes in Enlightenment thinking but at the same time uses the materiality of books as a way of finding a space in society.
\end{abstract}

\section{Keywords}

MuVIM; Specialized libraries; Museums,; Enlightenment; Graphic design.

\section{UNA BIBLIOTECA VINCULADA A UN CENTRO MUSEÍSTICO}

La biblioteca del MuVIM es una biblioteca de museo y, como tal, pertenece al grupo de las llamadas bibliotecas especializadas, cuya consolidación se produce en la segunda mitad del siglo XX como consecuencia del aumento de información y de la necesidad de tratar, de manera eficaz, el almacenamiento y difusión de parcelas concretas del saber.

Las vinculadas a centros museísticos tienen, además, la labor de apoyar las actividades que realiza el museo colaborando con material bibliográfico y documental, los planes y programas de exposiciones, investigación y promoción de la cultura. Al tratarse de bibliotecas adscritas a centros museísticos públicos están consideradas bibliotecas públicas especializadas y destinadas a un público interesado en la especialización del centro.

La biblioteca del Museu Valencià de la Il·lustració i de la ModernitatMuVIM, inaugurada el 20 de octubre de 2004, nacía como uno de los tres pilares básicos del museo, junto con el área de exposiciones y el centro de estudios. Al tratarse de un "museo de las ideas" (VEGAS, Carolina, 2006) y teniendo en cuenta que éstas se materializan en textos, su fondo bibliográfico se convertía en la colección patrimonial del museo. En la biblioteca es donde se reúnen, conservan y difunden los textos en los que 
se materializan las ideas del pensamiento ilustrado y su repercusión en la sociedad actual.

Como corriente de pensamiento que dominó Europa durante el siglo XVIII, la Ilustración tenía como principal propósito dirigir el mundo hacia el progreso, sacándolo del largo periodo de superstición, irracionalidad y tiranía. Este movimiento trajo consigo el marco intelectual en el que se producirían las revoluciones: Guerra de la Independencia de los Estados Unidos y Revolución francesa, así como el auge de Capitalismo y el nacimiento del Socialismo.

Las tres grandes ideas sobre las que se apoyaba la Ilustración eran la razón, la naturaleza y el progreso; ideas que pretendían difundir el saber e iluminar las zonas que habían estado hasta entonces sumidas en las tinieblas, aquello que Kant resumió en la frase Sapere Aude! (Atrévete a saber). Por todo ello, la biblioteca del MuVIM trata de ser un espacio de reflexión, investigación y exposición de un período en que el "saber" ocupaba un lugar importante en la sociedad.

\section{ANTECEDENTES: LA BIBLIOTECA GENERAL DE LA DIPUTACIÓN}

La biblioteca del MuVIM ha asumido los fondos y las funciones de la biblioteca general de la Diputación y, como tal, se ha convertido en biblioteca-depósito de la actividad editora de la Corporación con la función de reunir, conservar y difundir las publicaciones editadas por esta institución, además de asumir los fondos que la misma reunió a lo largo de su historia.

La Diputación de Valencia inició su colección bibliográfica hace casi una centuria, consciente de que su papel en la sociedad no era sólo administrativo sino también cultural. Dentro de esta concepción, no sólo se preocupó de crear y subvencionar instituciones culturales valencianas, como la creación en 1915 del Centro de Cultura Valenciana $^{2}$ sino que, además, apoyó la edición del libro valenciano ejerciendo un papel promotor de la cultura. Fue a partir de ese momento cuando comenzó a adquirir libros que, poco a poco, irían formando la colección de la biblioteca de la Diputación, de ahí la importante colección de obras de temática valenciana y editadas en Valencia durante la primera mitad del siglo XX que integra su fondo bibliográfico.

Unos años después la Corporación provincial tomaba conciencia de la importancia que suponía para la vida moderna el acceso a la cultura y lo necesario que era una Biblioteca como órgano difusor de ésta. En 1926, coincidiendo con la instauración en España de la Fiesta Nacional del Libro", se procedía a la creación de la biblioteca: "se ha iniciado por esta Diputación una Biblioteca, que si bien resulta modesta por la cuantía de sus fondos, reviste marcado interés, así por la materia sobre que versan los ejemplares que la integran, como por contener muchos de ellos dedicatorias autógrafas" $"$.

En 1947 se creaba la Institució Alfons el Magnànim (GABARDA, Vicent, 1997). El hecho de que durante más de treinta años los cargos de director de esta institución y de archivero-bibliotecario de la Corporación recayeran en la misma persona, D. 
Arturo Zabala, hizo que las publicaciones que adquiría la institución se integraran en la biblioteca general. Años después, la biblioteca general también asumía otras colecciones: la Cervantina, adquirida por compra en 1952; la biblioteca del padre Alfons Roig, donada en 1985; la colección de obras de teatro, adquirida por compra en 1987; y, finalmente, la de cartografía valenciana histórica, por compra en 1997. Podemos, pues, hacernos una idea de la riqueza cultural y el valor patrimonial que atesora.

La Biblioteca general comenzaba una nueva andadura a finales del año 1999. Por Decreto de Presidencia $n^{\circ} 10878$, de 16 de diciembre de 1999, se procedía a la reestructuración del área de cultura y, por Acuerdo Plenario de 22 de diciembre de 1999, la Corporación acordaba "el traslado de los fondos bibliográficos dependientes del Archivo-Biblioteca a la Red de Museos de la Corporación”.

En el intervalo de seis meses se procedía al traslado del fondo bibliográfico de un espacio a otro. El plan de actuación fue el siguiente: en primer lugar se seleccionaron, de entre el total de la colección, aquellos libros que iban a quedarse para formar la biblioteca auxiliar del Archivo General de la Diputación y los que iban a trasladarse. En segundo lugar, se procedió a cumplir el Acuerdo del Pleno, adoptado en la Sesión Plenaria celebrada el día 18 de abril de 2000, referente a la cesión temporal de la "Colección Cervantina" a la Biblioteca Valenciana ${ }^{5}$.

El resto de la colección se trasladaba al MuVIM, un espacio museístico nuevo, una entidad cultural emergente, novedosa y con proyección de futuro. La falta de equipamiento de la biblioteca, de presupuesto y de personal impidió que pudiera abrirse al público en las mismas fechas en las que se inauguraba el museo (junio de 2001). Tendrían que pasar unos años hasta que, en 2004, un cambio en la dirección del museo fuera el comienzo de una nueva etapa.

\section{ORGANIZACIÓN DE LA BIBLIOTECA DEL MUVIM}

El entusiasmo con que el nuevo director, D. Román de la Calle, asumió el proyecto y su capacidad para trasmitirlo a su equipo hizo que, pocos meses después, la biblioteca se abriera al público convirtiéndose su inauguración en el primer acontecimiento de la nueva etapa del MuVIM.

Al tratarse de un "museo de las ideas", la colección patrimonial del museo la formaba su fondo bibliográfico, de ahí las palabras de su director: "El MuVIM no es un museo que tiene una biblioteca; el MuVIM es un museo que gira alrededor de su biblioteca".

\subsection{Edificio: forma y función}

El principio básico que debe regir el diseño de una biblioteca es el de "función". Es importante establecer cuáles son los fines de una biblioteca para concebir el espacio que la va a albergar, porque los principios de utilidad, belleza y economía deben coexistir sin un divorcio entre forma y función.

El edificio del MuVIM, diseñado por el arquitecto sevillano Guillermo Vázquez Consuegra, está formado por dos volúmenes alargados, dispuestos casi en paralelo, que convergen en un gran espacio, el vestíbulo, consiguiendo así una imagen unitaria 
y compacta que es lo que pretendía el arquitecto: “... edificio que se mueve a medio camino entre su condición de objeto ensimismado, de artefacto aislado, de pabellón en el parque, condicionado por su programa de usos y su voluntad de aceptar el papel activo en la recalificación de su entorno urbano" (VÁZQUEZ CONSUEGRA, Guillermo, DÍAZ, Pedro, CASERO, Íñigo, 2001).

En la segunda planta del cuerpo, destinado a administración, se ubica la biblioteca, iluminada a través de una secuencia de lucernarios en su cubierta, orientados a Norte. La luz cenital que la ilumina y el diseño de la misma son de una gran belleza arquitectónica, pero donde espacio y función no siempre van a la par. Así pues, ante la necesidad de conseguir un espacio que ofreciera garantías de seguridad, la zona reservada a trabajo técnico se destinó a depósito, pasando el personal de la biblioteca a compartir espacio con los usuarios en la misma sala de lectura; de esta manera se consiguió crear un depósito, con armarios compactos, donde ubicar el material bibliográfico y documental más valioso.

\subsection{Organización del espacio}

Una vez organizado el continente se organizó el contenido. Concluido el trasladado de los fondos bibliográficos se procedió a una selección porque todo lo trasladado no era susceptible de formar parte de la colección del MuVIM, de ahí la necesidad de una selección muy controlada. Tras ésta, se procedió a su ubicación física después de responder a las siguientes preguntas: ¿Quiénes van a ser nuestros usuarios? ¿Cuáles sus necesidades informativas? ¿Cómo satisfacer de forma rápida y eficaz sus necesidades de información? Se contaba con una sala de lectura y tres depósitos, uno de ellos junto a la misma sala de lectura que se organizó como zona de libre acceso, disponiendo allí el fondo de mayor uso.

En cuanto al contenido del fondo bibliográfico, éste debía cubrir la temática específica del museo: el pensamiento ilustrado y su repercusión en la modernidad; pero la historia del pensamiento o la historia de las ideas es un concepto tan amplio que resulta difícil delimitarlo. Lo mismo ocurría al analizar el concepto Ilustración.

Disponíamos de un considerable fondo procedente de la biblioteca general que abarcaba diferentes áreas del saber $\mathrm{y}$, por tanto, contábamos con una biblioteca enciclopédica. La idea del saber enciclopédico nos ayudó a decidirnos por la utilización de la Clasificación Decimal Universal (CDU) para la organización física del fondo de libre acceso, pero marcando un carácter histórico ${ }^{6}$. El resto se ubicaba en depósitos de acceso restringido.

En el depósito de armarios compactos se ubicó el fondo antiguo procedente de la biblioteca general, el fundacional y la colección Alfons Roig conscientes de que, en una biblioteca patrimonial como la del MuVIM, la función de comunicación y atención al investigador no debe estar reñida con la de conservación. Todo este trabajo se realizó de una manera planificada y organizada, convencido de la importancia de esta labor para la buena gestión de la biblioteca. 


\subsection{Fondos}

Cuando se inauguró la biblioteca ofrecía un fondo bibliográfico de más de 20.000 volúmenes, fruto de la unión de tres importantes colecciones, más una cuarta que se añadiría unos meses después:

3.3.1. El Fondo fundacional. Adquirido en los años $1998-99^{7}$ para formar el núcleo central de la biblioteca. Está formado por una selección de obras claves del pensamiento ilustrado, obras del ciclo revolucionario, obras de pensadores liberales y reaccionarios de la primera mitad del siglo XIX, etc. La obra cumbre es la Encyclopédie (1751-1772).

3.3.2. La Colección Alfons Roig. A lo largo de su vida el padre Alfons Roig Izquierdo (1903-1987) reunió casi 6.000 monografías y más de 180 títulos de revistas. Su fondo es muy variado: filosofía, estética, arte, liturgia y teología, novela, ensayo y poesía. Cuenta además con un importante fondo antiguo, como resultado de su afición por la bibliofilia.

3.3.3. La Biblioteca General de la Diputación de Valencia. Además de los libros editados por la Corporación provincial a lo largo de su historia, tiene una importante colección de obras de temática valenciana. Cuenta, también, con un importante fondo antiguo y una colección cartográfica valenciana de los siglos XVII al XX.

3.3.4. La biblioteca de la Institució Valenciana d'Estudis i Investigació. En marzo de 2005 se incorporaba la biblioteca de la antigua IVEI, que contiene obras de pensamiento político-social y cultural que destacaron en los años ochenta del siglo XX en el ámbito internacional.

Entre las funciones que un museo debe realizar en la sociedad actual la investigación científica resulta decisiva. El fondo bibliográfico debe ser una herramienta imprescindible para documentar y preparar exposiciones, actividades culturales, publicaciones, etc.; y, como centro educador y divulgador, la biblioteca debe también promover el estudio y la investigación de la materia específica del museo. Por ello, debemos ser muy exigentes en la toma de decisiones sobre la composición de los fondos. Es necesaria una política clara y bien definida en el desarrollo o ampliación de la colección, centrada en la selección, adquisición y evaluación de los materiales. Los parámetros de este desarrollo tienen que ser fijados por los bibliotecarios y los técnicos del museo a partir de los resultados de evaluación de las colecciones existentes y de los objetivos institucionales.

\subsection{Servicios}

Los servicios que ofrece la biblioteca del MuVIM son los mismos que cualquier otra biblioteca de su clase: información bibliográfica y documental (servicio de referencia e información), préstamo personal, interbibliotecario e institucional, reprografía, etc. Como biblioteca patrimonial ofrece, además, el servicio de cesión temporal de obras para exposiciones. La biblioteca del MuVIM presta obras tanto para las exposiciones del propio museo como para otras instituciones, siempre y cuando cumplan los 
requisitos establecidos para ello: estado físico del documento, condiciones de la sala donde se va exponer, seguro a todo riesgo y de clavo a clavo, etc.

\section{UNA BIBLIOTECA CON CERTIFICADO DE CALIDAD}

La biblioteca del MuVIM, al igual que el museo, está certificada (Norma ISO 9001:2008). Eso significa que su sistema de gestión está normalizado, que los procesos de prestación de servicio han sido definidos e implantados y que éstos se gestionan para satisfacer las necesidades y expectativas de sus clientes.

Esto nos obliga a planificar los servicios bibliotecarios pensando siempre en mejorar la calidad. Para ello hay que identificar las necesidades, establecer unas metas y objetivos bien definidos y evaluarlos periódicamente. El Comité de calidad se reúne trimestralmente para hacer el seguimiento de los procesos implantados, los cuales se valoran a través de una auditoria anual.

Todos los servicios que ofrece la biblioteca tienen como finalidad última satisfacer al usuario. Pero somos conscientes de que cuantificar los beneficios que para los usuarios reporta un buen servicio de biblioteca no es fácil; sin embargo éstos existen y los podemos medir en términos de calidad de servicio y satisfacción de usuarios. Evaluar nuestros servicios supone una reflexión objetiva de nuestro trabajo, poner de manifiesto cuáles son los puntos fuertes y débiles de nuestra organización y reorientar en su caso los servicios hacia unos planteamientos más adecuados, estableciendo nuevas prioridades.

Pero todas estas tareas no pueden realizarse de forma unilateral, sino formando un todo con el resto del museo. Por ello, es importante conocer e implicarse en la misión y visión del museo.

La misión del MuVIM es proveer de investigación, educación, divulgación y deleite a través de los servicios de exposiciones, biblioteca, centro de estudios e investigación, propuestas educativas y otras actividades paralelas, todas ellas encuadradas en el ámbito de la Ilustración y la Modernidad. El MuVIM quiere ser un puente entre la sociedad y la Universidad, completando el panorama cultural valenciano.

Así pues, la biblioteca debe servir de apoyo bibliográfico y documental al MuVIM, colaborando con sus actividades, sobre todo con aquellas especializadas (exposiciones, congresos, publicaciones, etc.) y destinadas a un público determinado.

La visión del MuVIM abarca cuatro importantes aspectos:

- Ser un museo de referencia en cuanto a las figuras y contenidos claves de la Ilustración.

- Ser un museo de referencia de las Vanguardias europeas en colaboración con entidades europeas.

- Programas culturales: cine, fotografía.

- Desconcentración: actividades a realizar fuera del espacio del MuVIM destinadas a enseñanza secundaria. 
La visión del MuVIM es la que marca la especialización del fondo bibliográfico. Nuestro plan de actuación es, en primer lugar, convertir la biblioteca en una biblioteca especializada en las figuras y contenidos claves de la Ilustración y, en segundo lugar, formar un fondo bibliográfico especializado en fotografía y diseño gráfico, dado que las exposiciones temporales que se realizan en el MuVIM recogen esta temática: arte sobre papel (carteles, fotografías, libros ilustrados, tipografía, grabados, etc.).

\section{5. ¿UNA BIBLIOTECA DE MUSEO O UN MUSEO BIBLIOTECA?}

El término "Museo", procedente del griego, significa lugar destinado a las musas. En Roma se utilizaba el término "museum" para designar ciertos lugares donde se desarrollaban discusiones filosóficas, como el famoso Museum de Alejandría, nombre que tomó su célebre biblioteca. Pronto comenzó a utilizarse este término para designar tanto las bibliotecas como lo que hoy consideramos museos. Coincidencias y discrepancias que han continuado a lo largo de la historia (LÓPEZ DE PRADO, Rosario, 2003).

La Encyclopédie dedica doce páginas al término "Bibliothèque" pero no recoge el de museo $^{8}$. La ley 16/1985 de 25 de junio, del Patrimonio Histórico Español define las bibliotecas y museos:

- Son Bibliotecas las instituciones culturales donde se conservan, reúnen, seleccionan, inventarían, catalogan, clasifican y difunden conjuntos o colecciones de libros, manuscritos y otros materiales bibliográficos o reproducidos por cualquier medio para su lectura en sala pública o mediante préstamo temporal, al servicio de la educación, la investigación, la cultura y la información.

- Son Museos las instituciones de carácter permanente que adquieren, conservan, investigan, comunican y exhiben para fines de estudio, educación y contemplación conjuntos y colecciones de valor histórico, artístico, científico y técnico o de cualquier otra naturaleza cultural.

Tal como afirma Rosario López de Prado, los significados de los dos conceptos no son muy diferentes, ya que ambas instituciones se encargan de custodiar bienes culturales y persiguen fines similares: estudio, deleite, investigación y difusión.

Las ideas ilustradas generalizaron el concepto de "democratización de la cultura", conscientes de la importancia de educar al pueblo para mejorar su calidad de vida. Estos primeros museos y bibliotecas públicas eran de carácter enciclopédico y en ellos era difícil delimitar dónde comenzaba y finalizaba la biblioteca y el museo, porque era todo uno.

Es a partir del siglo XVIII cuando los museos y las bibliotecas adquieren carácter público, aunque su acceso fuera al principio muy limitado. Además, fueron los ilustrados quienes hicieron posible que las colecciones de arte y objetos preciosos, que habían coleccionado la realeza y las clases pudientes durante años, pudieran abrirse al público. El primer museo público fue el British Museum (1753) y estaba formado por 
museo y biblioteca.

La colección bibliográfica patrimonial del MuVIM, que recoge en el soporte "libro" las ideas que configuran la especialización de este museo tiene, al igual que cualquier colección museística, un carácter permanente. Se adquiere con cargo a la partida presupuestaria de inversiones y se inventaría como un bien patrimonial de la Diputación de Valencia.

Si partimos de que "documento" es un mensaje sobre un soporte, podemos considerar el libro como el mejor soporte para alojar un mensaje, tal como apunta José Antonio Pérez-Rioja:

"El libro es el mensaje más perdurable a través de los tiempos por el hecho esencial de que le cabe una función insustituible: la de ser expresión más fiel de las ideas y los sentimientos y el depósito, o la fuente, de valores y verdades permanentes, lo que no sólo permite augurarle continuidad, sino el que signifique, también, seguridad y esperanza para el futuro" (PÉREZ-RIOJA, José Antonio, 1997).

La colección patrimonial del MuVIM está formada por documentos, cuya plasmación física no es un resto fósil o lítico, ni un lienzo pintado, ni un apero de labranza, sino el libro impreso fruto de las ideas que se forjaron en un período de tiempo determinado y que nos han llegado a través del desarrollo de la imprenta.

Todo esto nos lleva a replantearnos nuestro futuro y a marcar un plan de actuación que una el antes y el después, pero también ese doble carácter que está transmitiendo el MuVIM a la sociedad: Por una parte, un museo con una exposición permanente basada en la historia del pensamiento y, por otra, un museo con una proyección artística de "arte sobre papel": grabados, carteles, tipografía, etc., lo que denominamos "Diseño gráfico". Un concepto actual pero cuyos orígenes se remontan a la historia de la invención de la imprenta, pues cualquier impreso puede ser objeto de estudio y de análisis para conocer el diseño gráfico con el que fue creado. Porque, a lo largo de la historia de la imprenta, el impresor o creador del producto "libro" ha querido producir un buen producto al mejor coste, de ahí la importancia que tiene recordar que la historia de la imprenta es también la historia del diseño gráfico.

Si analizamos el concepto "diseño" entenderemos que el producto "libro" cumple con las tres funciones del diseño: la práctica, la estética y la simbólica. La práctica porque se trata de un producto que se elabora para cubrir unas necesidades: enseñanza, información, deleite, etc.; la estética porque el editor-impresor trata de realizar un producto atractivo (tipografía, ilustraciones) que producirá en el usuario una satisfacción visual/emocional; y la simbólica, porque determina la imagen del usuario, quien a través de la posesión de ese producto y de la información que allí contiene, demostrará su pertenencia a un grupo social e incluso ideológico.

Por todo ello, la biblioteca del MuVIM puede convertirse en un referente, no sólo para los estudiosos de la historia del pensamiento ilustrado y su repercusión en la 
modernidad, sino también para los estudiosos de la historia del libro, de la tipografía y del diseño gráfico. Démosle, pues, esa otra visión a los libros, la artística. Consideremos el libro bajo esa doble función: transmisor de ideas (contenido, fondo) e informador de la evolución de la imprenta y del diseño gráfico y, como tal, con el mismo valor que cualquier pieza museística (materialidad, forma).

Actualmente, en la sociedad de la información y la comunicación que estamos viviendo, se dice que el libro digital acabará desplazando al libro impreso. Si esto ocurre las bibliotecas se convertirán en museos y será una vuelta a sus orígenes. La biblioteca del MuVIM seguirá custodiando las ediciones de los siglos XVIII y XIX que permitieron que las ideas de los pensadores ilustrados fueran conocidas por Europa y América, ideas que han permitido el estado de desarrollo y progreso alcanzado.

\section{Notas}

1. Este trabajo es un resumen de otro más extenso que iba a formar parte del libro que el profesor Román de la Calle preparaba para conmemorar el primer sexenio de su gestión (desde la primavera de 2004 hasta la de 2010). Tras su dimisión el proyecto se ha truncado. Sirvan, pues, estas páginas como un pequeño homenaje a quien fue un buen director del MuVIM, una persona íntegra y un amigo para todos los que formábamos su equipo.

2. ARCHIVO GENERAL Y FOTOGRÁFICO DE LA DIPUTACIÓN DE VALENCIA (ADPV), A.3.12/v. 13.

3. Real Decreto de 6 de febrero de 1926, firmado por el Rey Alfonso XIII.

4. ADPV, A.3.12/v. 24, p. 97.

5. ADPV, A.3.4.5, cj. 61, exp. 33.

6. Todas las materias están representadas pero desde un punto de vista histórico, no hay tratados de materias científicas específicas pero hay historia de la medicina, de la ciencia, de la ingeniería, etc.

7. Se adquirió durante la Presidencia de D. Manuel Tarancón, creador de este museo, y fueron seleccionadas por Rafael Company y Marc Borrás, primer director y subdirector del museo.

8. Tan sólo define la definición clásica de "lugar destinado a las musas".

\section{Referencias bibliográficas}

GABARDA, Vicent, (1997), Institución Alfons el Magnánimo, Institució Valenciana d'Estudis e Investigació (1947-1997), València, Edicions Alfons el Magnànim-IVEI.

LÓPEZ DE PRADO, Rosario (2003), "Bibliotecas de museos en España: características específicas y análisis DAFO” en Revista General de Información y Documentación, 13, n 1, pp. 5-35. Disponible en:

<http://revistas.ucm.es/byd/11321873/articulos/RGID0303120005A.PDF>

[Consulta: 12 de abril de 2010].

PÉREZ-RIOJA, José Antonio (1997), Elogio del libro. Salamanca, C.E.G.A.L.

VÁZQUEZ CONSUEGRA, Guillermo, DÍAZ, Pedro, CASERO, Íñigo (2001), "MuVIM” en TC Cuadernos, vol. 9, $\mathrm{n}^{\mathrm{o}} 49$.

VEGAS, Carolina (2006), "MuVIM, del anonimato al nombre propio" en Archivo de Arte Valenciano, Valencia, $n^{\circ} 87$, pp. 209-227. 